\title{
The Italian Society for Digestive Endoscopy (SIED) accreditation and quality improving project based on international standards
}

\section{다 (1) $(2)$}

\author{
Authors \\ Luisa Riccardi ${ }^{7}$, Francesco Torresan ${ }^{8}$ \\ Institutions \\ 1 Valduce Hospital, Como, Italy \\ 2 Chieti University, Chieti, Italy \\ 3 Pordenone Hospital, Pordenone, Italy \\ 4 Pistoia Hospital, Pistoia, Italy \\ 5 Florence Hospital, Florence, Italy \\ 6 Ferrara University, Ferrara, Italy \\ 7 Perugia Hospital, Perugia, Italy \\ 8 Bologna University, Bologna, Italy \\ submitted 4.7.2019 \\ accepted after revision 3.12.2019 \\ Bibliography \\ DOI https://doi.org/10.1055/a-1096-0219 | \\ Endoscopy International Open 2020; 08: E338-E345 \\ (c) Georg Thieme Verlag KG Stuttgart · New York \\ eISSN 2196-9736 \\ Corresponding author \\ Giancarlo Spinzi, Valduce Hospital, Via Dante 11, 22100 \\ Como, Italy \\ Fax: +0039 031308047 \\ gispinz@tin.it \\ Appendix \\ Online content viewable at: \\ https://doi.org/10.1055/a-1096-0219
}

Giancarlo Spinzi ${ }^{1}$, Angelo Milano ${ }^{2}$, Piero Brosolo ${ }^{3}$, Paola Da Massa Carrara ${ }^{4}$, Maurizio Labardi ${ }^{5}$, Alberto Merighi ${ }^{6}$,

\section{ABSTRACT}

Background and study aims Accreditation of endoscopy services, using valid quality indicators, may address failures to comply with quality standards between endoscopy services. The aim of this work was to present the Italian Society for Digestive Endoscopy (SIED) accreditation model and its effectiveness.

Methods A team of eight endoscopists identified quality indicators derived from international guidelines and assessed them in each center voluntarily requesting accreditation. During a 1-day site visit, two expert endoscopists, the representative of the independent and international administrative certification body and a professional nurse evaluated the endoscopy center, by direct observation of the endoscopy team and examination of the medical records

Results In all centers we noted shortcomings in instrument reprocessing. In 30 of 40 centers (75\%) the information in the nursing charts was incomplete. Sampling for Helicobacter pylori had not been done in 12 of 40 centers ( $30 \%)$. In six of 40 centers $(15 \%)$ the adenoma detection rate for each endoscopist had not been evaluated. Post-polypectomy intervals were inappropriate in 12 of 40 centers (30\%). We noted a statistically significant difference $(P<0.001)$ between the answers to the SIED checklist of indicators submitted to the inspection team for accreditation before the site visit and the situation found for colonoscopy on site. As of June 30, 2018, 18 endoscopy centers had been accredited and 10 centers had not yet being accredited because they had not completed the measures to correct points raised at the visits.

Conclusions Numerous Italian endoscopy centers fail to meet important quality indicators. Our accreditation program can provide means for detecting these problems and correcting them by implementing SIED standards.

\section{Introduction}

In response to the article "To err is human" [1] and the problems related to quality and increasing healthcare costs, healthcare institutions are seeking ways to boost the quality of care provided for citizens. Many proposals have been put forward, but evidence of their effectiveness is still limited.

Guidelines are fundamental in healthcare planning, evaluation and quality improvement. However, they are not consistently translated into policy or practice [2,3], even with a multifaceted implementation strategy [4]. These findings cause concern 
given the intensity and the cost of efforts to generate an everincreasing body of guidelines, that are all too often not used [5, 6].

Digestive endoscopy holds a key role in diagnosis and treatment of many gastrointestinal diseases, and when it is done properly it is effective, safe and well tolerated. However, ratings for various key indicators, such as completeness of the colonoscopy, post-polypectomy follow-up, adenoma detection rates, and others tend to vary widely. The literature bears witness to the broad variability of results, not only between endoscopists but also between hospitals [7].

A recent survey in 282 hospitals throughout Italy reported significant differences in quality and various failures to comply with standards [8], and similar findings appear in the international literature [9]. Accreditation using validated quality indicators might help solve some of the problems. However, there are doubts on account of the workload they would involve for physicians and hospital structures, and on their actual effectiveness $[10,11]$. A 2016 Cochrane review noted the lack of papers on the effectiveness and cost-effectiveness of external inspection systems for hospitals [12]. Nevertheless, fairly recently, various critical points and knowledge gaps have been identified and addressed.

Here we present an accreditation model established by the Italian Digestive Endoscopy Society (SIED) as part of its statutory tasks for improving and unifying the care provided by endoscopy services throughout Italy.

\section{Methods}

In 2014 the SIED decided to design and implement an accreditation program for Italian endoscopy services, in collaboration with Kiwa-Cermet, an independent international certification organization with a specific healthcare section, and with the Italian association of healthcare technical operators (ANoTE), and the national gastroenterology nursing association (ANIGEA).

A team of eight endoscopists from different institutions, selected by the SIED council with at least 10 years' experience, was given the task of drafting professional and service standards meeting Italian requirements. The team's draft of these standards (Appendix 1) was assessed on the basis of an Estimate-Talk-Estimate method using face-to-face meetings with information derived from Italian and international literature, using the GRADE system (Appendix 2). These standards were discussed at weekly web meetings, then approved by the SIED and ANOTE-ANIGEA boards.

Priority was given to indicators that were broadly applicable in clinical practice, correlated with changes in outcomes, and validated whenever possible.

Clinical trial reports on which to base the choice of indicators were identified by a computerized search on Medline and review of the references of the relevant articles. When there were no such studies, the SIED team of eight endoscopists agreed on appropriate indicators. In case of disagreement on any particular requirement, the literature was reviewed again and approval or rejection was decided by a majority of the team members.

The team revised the indicators once a year, following the same methods and criteria, on the basis of any new data in the literature (latest revision June 2018). Feasibility of the requirements was assessed first of all in three endoscopy centers, differing in the number of examinations they did, their endoscopic techniques, where they were based in the country, and the complexity of the hospital structure. These standards are available to all SIED members and can be freely consulted on the site www.sied.it.

For each center voluntarily requesting accreditation, a selfassessment checklist is provided as a tool for evaluating how closely they comply with the standards established by the model before a site visit. The site visit to centers that apply lasts 1 day, and is carried out by two expert endoscopists, each with at least 10 years of endoscopy experience, the representative of the certification body, Kiwa-Cermet, who ensures the fairness of procedures and a professional nurse nominated by $\mathrm{AN}$ OTE-ANIGEA.

A list of 34 qualified experts - 22 doctors and 12 nurses was drawn up and they met, for agreement of opinions and actions, at two 1-day meetings held in the certification body's Bologna offices and annually at meetings during the national congress of the Italian Digestive Diseases Federation (FISMAD). Two of these qualified experts participated and reviewed outcomes of each site visit and drew up an action list that was fed back to the local units. Implementation of SIED standards was mandatory within a maximum of 4 months.

During the site visits to the endoscopy centers, the KiwaCermet representative inspected the center's documentation system, assessed the coherence of the mission and the vision, the methods used to achieve the goals, the methods for assessing the competence of the doctors, leadership, and management of human resources.

The two endoscopists assessed the pre-, intra- and post-procedural phases of gastroscopy, colonoscopy, percutaneous endoscopic gastroscopy (PEG), and endoscopic retrograde cholangiopancreatography (ERCP), directly examining at least 100 endoscopy reports for each method (paper or electronic) in any period, selected at random. The endoscopists and the nurse evaluated the endoscopy reports with a multidisciplinary approach. In September 2018 they also started checking endoscopic ultrasonography (EUS) in the centers that do this examination routinely.

The nurse and the endoscopists looked at the route taken as a patient was moved through the endoscopy unit, the nursing charts, instrument reprocessing and the technologies available. Patients were not asked for their opinion on the endoscopy services.

At the end of the day's visit the findings were presented and discussed in a meeting with the center's endoscopists, some of the nursing staff, and the representative of the medical and/or general management, the latter to approve relevant actions.

Any non-compliance that came to light during the site visit must be corrected by the endoscopy unit in the time allotted for the accreditation procedure, and the team then checked 
whether the unit had made all the corrective measures required. If the team could not decide whether the improvements were adequate, a majority decision was taken. If corrective measures had not been taken by the date set by the team, the SIED accreditation procedure allowed for further site visits, with the endoscopy center's agreement, for a fresh look at the standards and practical suggestions on how to achieve them. Accreditation lasts 2 years, at the end of which time a new site visit could be scheduled, if requested, for a new assessment. The SIED bore the costs for the site visit.

\section{Statistical analysis}

To analyse the differences between the criteria reported in the self-assessment as not met and those found on the on-site visit, we used a Student's $t$-test (IBM SPSS software, version 20). A two-sided $P \leq 0.05$ was considered statistically significant.

\section{Results}

Since the SIED accreditation scheme started in 2014 and up to June 30, 2018, 40 site visits had been made, and the data given here refer to the team's findings at each visit. As of June 30 , 2018, 18 endoscopy centers had been accredited. Ten of the accredited centers are in northern Italy, five in the center, and three in the south. As of June 30, 2018, 10 centers had not yet been accredited because they had not completed the measures to correct points raised at the visits.

- Fig. 1 shows the numbers of the SIED standards not met on the basis of the endoscopy centers' self-assessments submitted to the inspection team before the site visit and the number of deviations actually recorded during the visit, divided according to the procedure being assessed. PEG and ERCP findings refer to 29 of the 40 site visits.

For gastroscopy, 61 self-assessments differed from the SIED standards, and 67 were noted during the site visit (N.S.). For colonoscopy, 30 deviations from the standards were self-reported before the site visit and 93 after it $(P<0.001)$. For PEG, self-assessment reported 18 findings before the site visit, and 22 after the visit (N.S.) For ERCP, there were 24 self-assessed deviations and 19 after the visit (N.S.).

Points where the SIED standards were not met in the various centers, as reported by the representative of the Kiwa-Cermet Italia certification agency, and by the nursing representative, are represented in $>$ Fig. 2 . The most frequent failures noted during the site visit involved reprocessing the endoscopes (60 times), unsatisfactory compilation of the nursing charts (55 times), failure to complete periodic assessments of medical and nursing skills (34), poor assessment of expected targets (33) and incomplete or erroneous compilation of the endoscopy report (26).

Esophagogastroduodenoscopy quality indicators recorded during the site visits are reported in $\mathbf{~ F i g . ~} 3$. The most frequent criteria not met were the failure to test for Helicobater pylori when it would have been clinically advisable (12 times), not using the Prague classification for Barrett esophagus (11 times), not using the OLGA (Operative Link for Gastritis Assess-

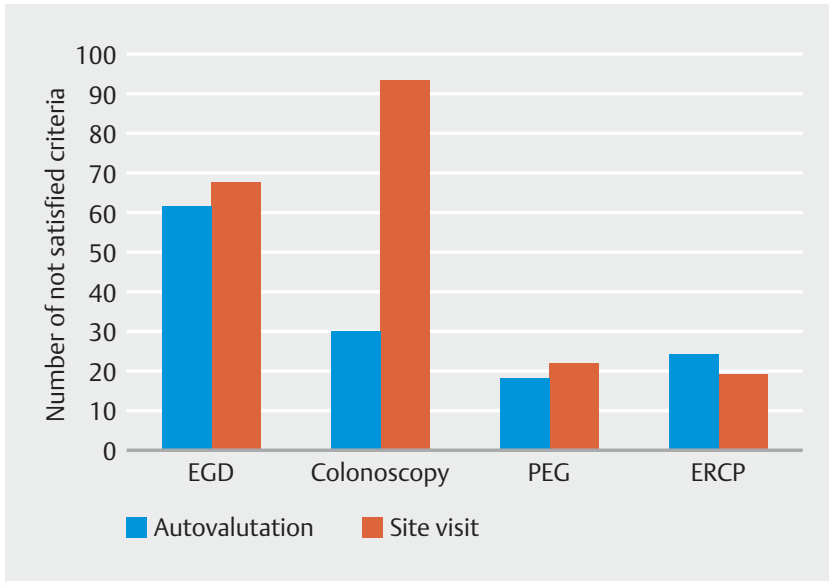

- Fig. 1 Criteria not met reported on the self-completed checklist before and after the SIED-ANoTE site visit, for each endoscopic procedure.

ment) classification (9 times) and inadequate follow-up for gastric ulcer (8 times).

Findings for colonoscopy reported by the endoscopists and assessment during the site visit are reported in > Fig. 4 . The most frequent unsatisfactory points were inadequate colon preparation (13 times), inadequate photographic documentation (13), inadequate post-polypectomy follow-up (12), postpolypectomy follow-up protocol not complying with guidelines (10). Endoscopists' assessments for PEG and results of the site visit inspection are set up in $\mathbf{F i g}$. 5 . The most frequent points were incomplete examination of all the anatomical tracts (12 times), lack of alternative positioning techniques (11), and inadequate documentation of the procedure (9).

Endoscopists' assessments for ERCP are shown in > Fig. 6. During the site visit 19 deviations from the standards were found, compared to 24 on the checklist submitted before the visit. The most frequent points noted were the lack of diclofenac or indomethacin prophylaxis for acute pancreatitis ( 5 times), the failure to give antibiotics for prophylaxis when required (4), and incomplete endoscopy reports (2).

\section{Discussion}

SIED accreditation indicated substantial differences between the hospitals visited in their compliance with standards; this is in line with previous reports $[2,8]$, and confirms the lack of compliance with guidelines [13]. We also noted a statistically significant difference between the answers to the SIED checklist of indicators submitted to the inspection team for accreditation before the site visit (most of the assessments were indicated as "excellent") and the situation found for colonoscopy on-site. This casts serious doubt on the utility of the frequent surveys that rely on participants' self-reports. Behaviors, attitudes or actions are indirect measures and are susceptible to self-reporting and social-desirability biases. Participants may overestimate their own expertise or knowledge or may wish to 


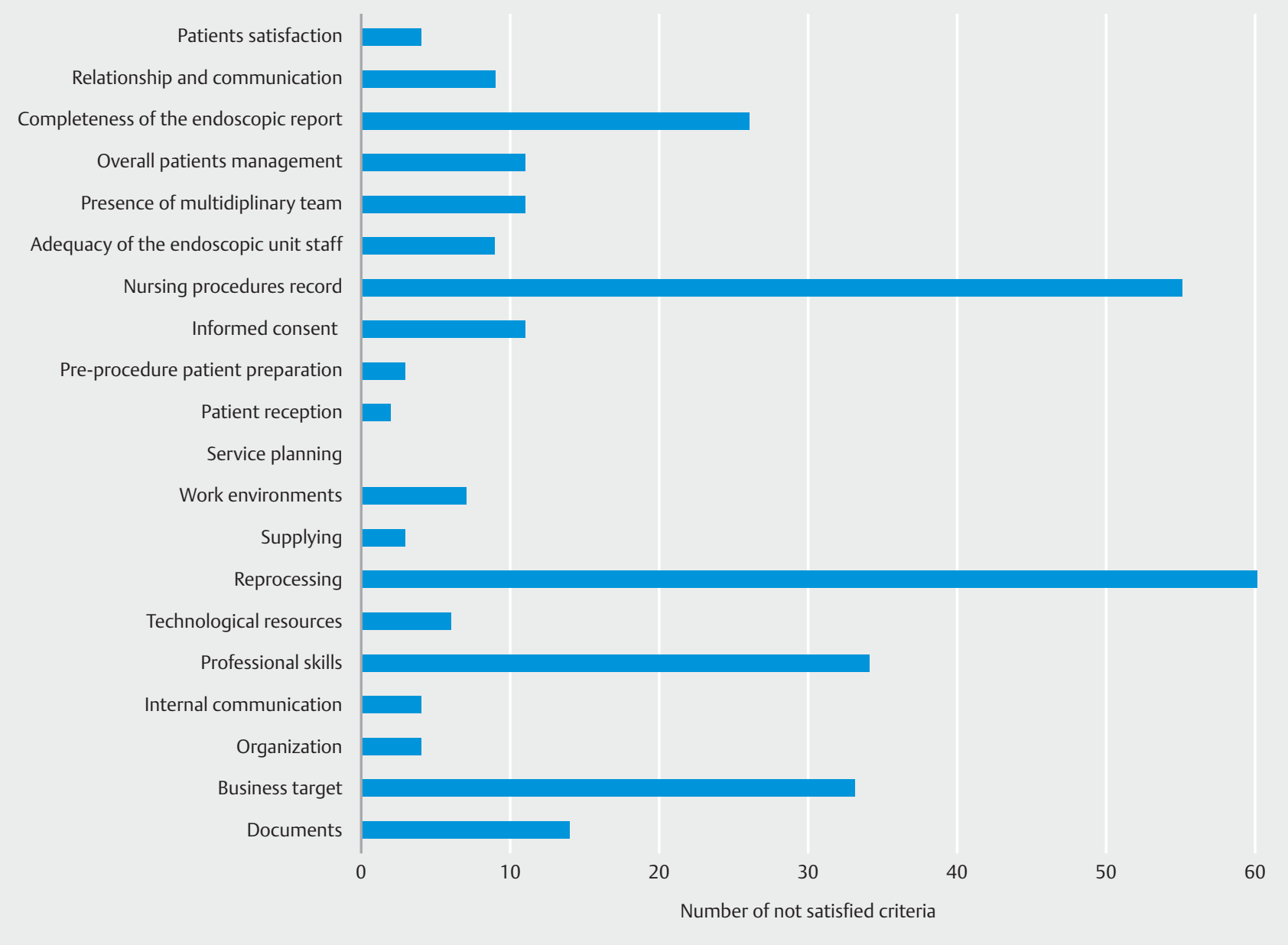

- Fig. 2 Criteria not met under each main checklist heading in 40 site visits. Please see Appendix $\mathbf{1}$ for complete explanation of the criteria.

limit embarrassment or answer in ways that make them "look better" [14].

Only the answers to the checklist for ERCP were lower than the deviations actually found during the site visit. This might reflect prompt introduction of SIED standards by endoscopists doing ERCP: In all the centers inspected they were far fewer than those doing other types of endoscopy.

Main differences between practice in the single centers and the guidelines were on the following points:

- Reprocessing instruments: The 60 findings referring to endoscope reprocessing come from $32 / 40$ site visits (80\%). These figures are particularly alarming because, although the transmission of infection in endoscopy has long been considered unlikely, since 2010 numerous reports have been published of infection due to multiresistant germs, mainly in ERCP $[15,16]$. These infections have occurred in American centers [17] and in Europe [18] and have been reported in the media in view of their clinical impact [19].

- Management of the nursing procedure records: In 30 of 40 centers (75\%), information in the charts was incomplete, but these records must be compiled as precisely as possible to ensure safety and the quality of the service. This has been stressed in the literature [20].

- Biopsies to check for $H$. pylori in gastroscopy: This test must always be done in patients with peptic ulcer diseases, mucosa-associated lymphoid tissue (MALT) lymphoma, noncardias gastric cancer. It has been repeatedly underlined in numerous articles [21] and guidelines [22]. In 12 of 40 centers (30\%) visited, sampling for $H$. pylori had not been done in compliance with the standards.

- Adenoma detection rate (ADR) in colonoscopy: This is the standard requirement for identifying early and precursor lesions, but many papers still report an overall interval cancer rate of $6.2 \%$ [23]. ADR is a key quality indicator recognized by professional organizations including the US Multi-Society Task Force on Colorectal Cancer, who describe it as the most important and highly variable measure of the quality of mucosal inspection during colonoscopy [24]. A prospective study by Kaminski in the Polish Colon Cancer Screening Program demonstrated the relation between the ADR and the incidence and mortality of interval cancers [25]. We found that in six of 40 (15\%) the head of the department did not calculate the ADR for each individual operator. 


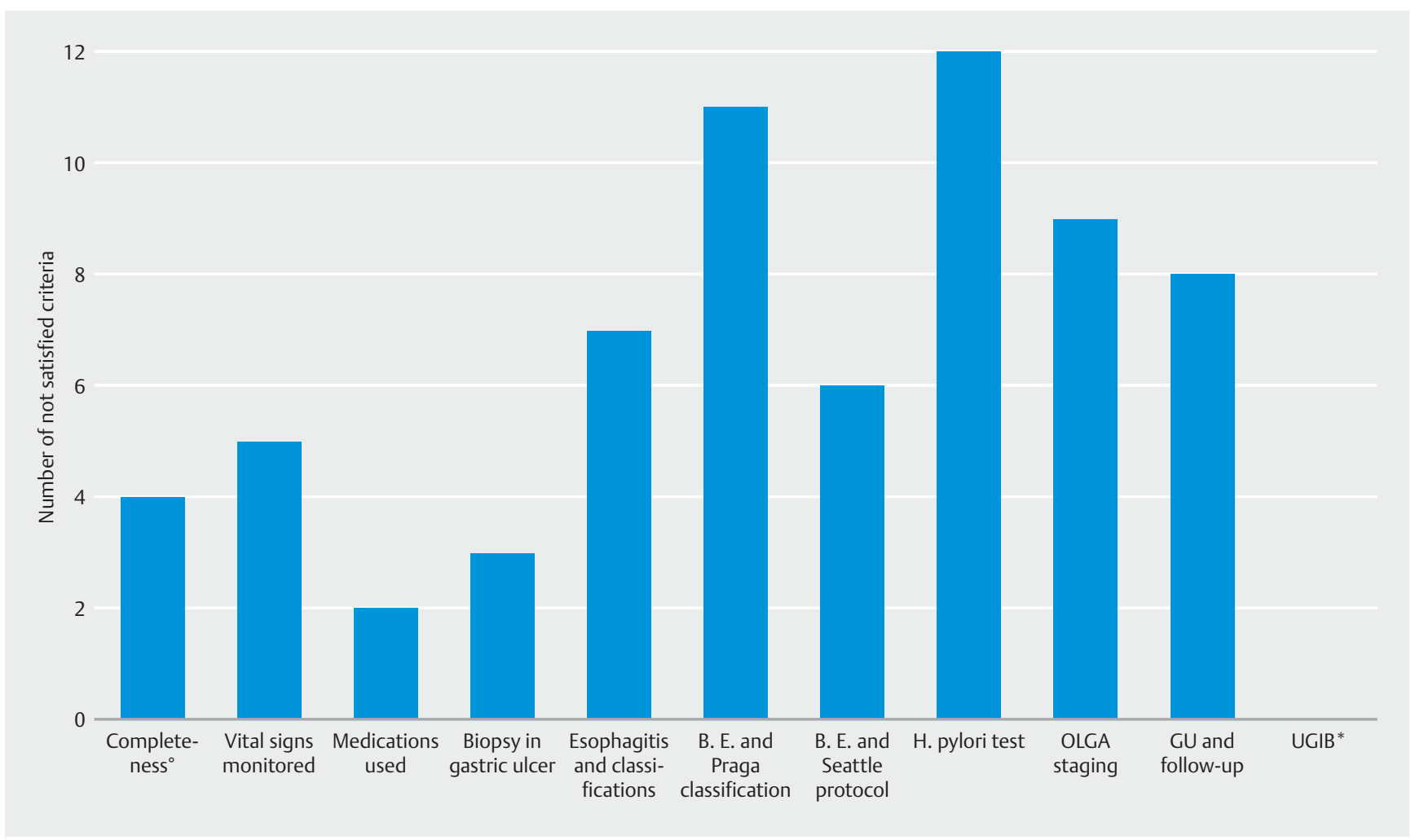

- Fig.3 Quality indicators for esophagastroduodenoscopy: frequency of criteria not met, according to the endoscopy report. B.E., Barrett esophagus; OLGA, Operative Link for Gastritis Assessment; GU, gastric ulcer; UGIB, upper gastrointestinal bleeding. Completeness implies a complete examination with photos of pathologic lesion(s) in particular. UGIB implies a full description of lesion(s), using Forrest classification, as necessary, with a multidisciplinary approach and adequate hemostatic techniques according to guidelines (e. g. combined technique in case of epinephrine injection or band ligation, preferred in case of variceal bleeding).

- Post-polypectomy follow-up in colonoscopy: Follow-up intervals after colonic polypectomy often differed from those recommended in the literature [9]. In general, the intervals were shorter than those recommended for colonoscopy, resulting in higher healthcare costs and avoidable risk for patients [26]. Post-polypectomy intervals were inappropriate in 12 of 40 centers (30\%).

- Complete endoscopic examination during PEG: 12 of 40 centers (30\%) did not reach the second duodenal portion, with retroversion and visualization of the cardias - as suggested in the literature [27].

- Post-ERCP prophylaxis with indomethacin or diclofenac: Systematic review and metaanalyses have confirmed that these two drugs are inexpensive, safe and significantly lower the risk-ratio for post-ERCP pancreatitis. Regrettably, four of 32 centers $(12.5 \%$ ) did not prescribe one of these NSAIDs immediately before or after ERCP.

All centers corrected the failures to meet the SIED criteria noted during the site visits, in the times set, before they could be accredited.

We believe that the accreditation procedure set up by SIED, respecting foreign experiences to some extent [28], has certain strong points. The system ensures that the endoscopy organization meets all the standards selected by SIED after on-site in- spection of clinical documentation, endoscopy procedures, and efficient instrument reprocessing. SIED accreditation involves an integrated procedure that assesses most endoscopic examinations and compliance with professional guidelines, which should boost efficacy of endoscopy and optimize patient outcomes [29].

Members of the site-visit team frequently talked about the issues related to the endoscopy visits at meetings in the certification body's offices, during the annual congress of the Italian Digestive Diseases Federation (FISMAD) and at weekly web meetings.

Unlike other accreditation schemes, this model directly assesses the endoscopy reports; processes, including reprocessing; and facilities - with only marginal regard to the structure of the center itself, which is a matter for other types of accreditation and generally does not come under the responsibility of the head of the endoscopy center.

Our model gives a "snapshot" of work in an endoscopy center and corrects poor practice. It cannot guarantee continued improvement, which implies periodical monitoring, although this is contemplated by our program. Self-selection of sites entering the SIED accreditation program may represent a limit of our action and may highlight only the tip of the iceberg. We do believe, however, that SIED accreditation, comprising preparation for the visit, defining and monitoring the steps taken for 


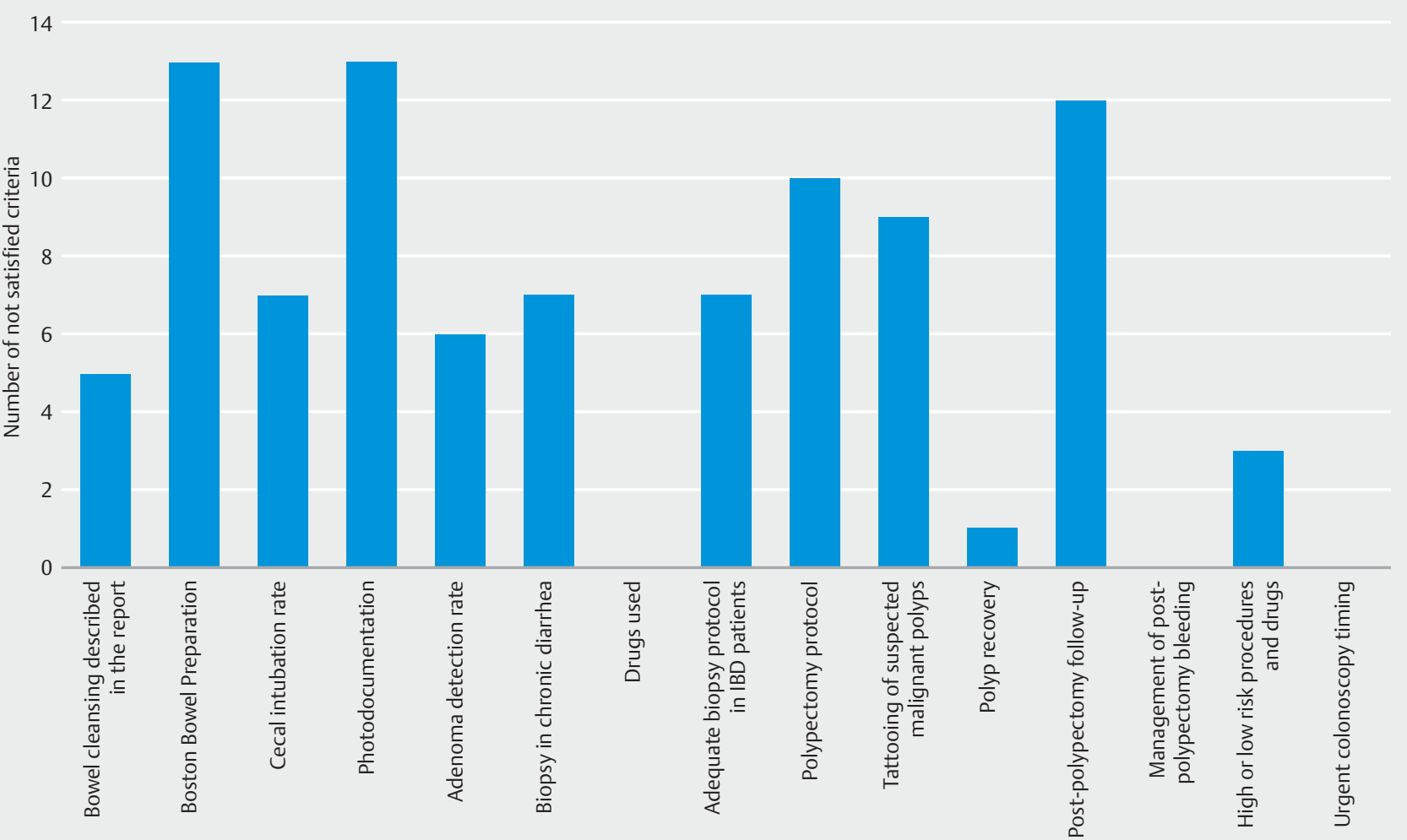

- Fig.4 Quality indicators for colonoscopy. Frequency of criteria not met according to the endoscopic report. Please see Appendix 1 for complete explanation of the criteria.

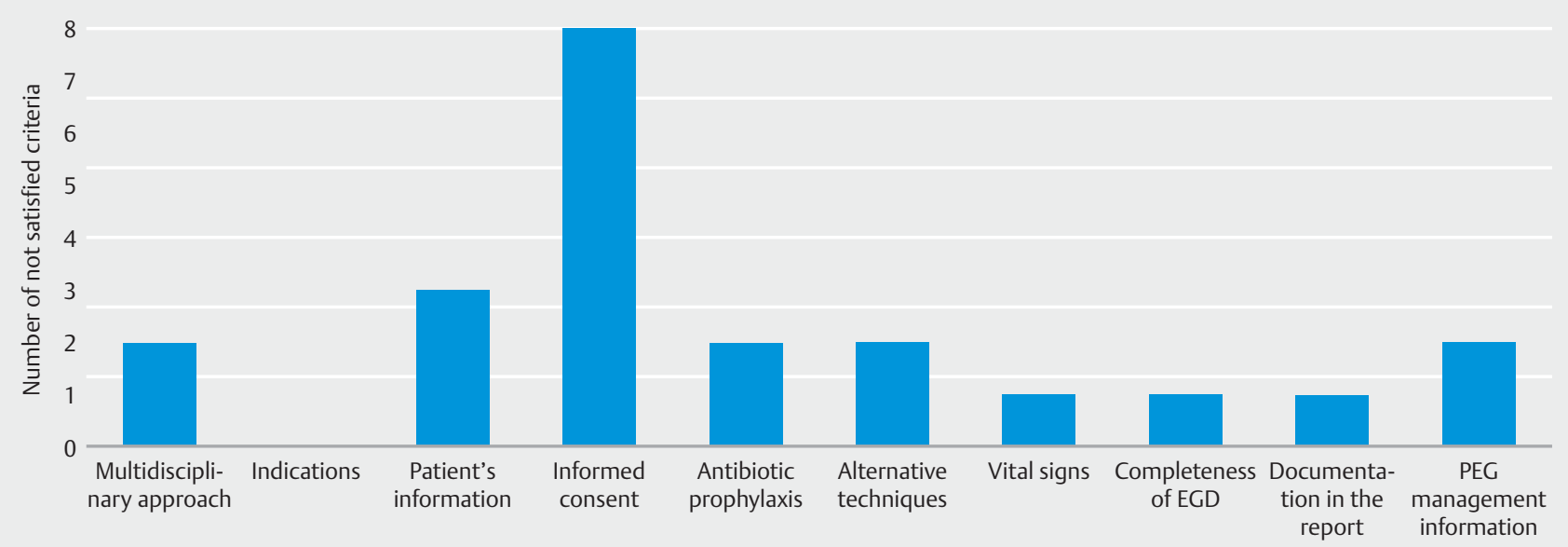

Fig. 5 Quality indicators for PEG: frequency of criteria not met according to the endoscopic report. Please see Appendix $\mathbf{1}$ for complete explanation of the criteria.

improvement, and subsequent reassessment, should trigger improvements in quality. Moreover, hospital health management is directly involved in the initiative.

Our aim and desire is to achieve the same results as the English Joint Advisory Group on Gastrointestinal Endoscopy, which has strong leadership at national level, offers guidance and pro- cesses to support the endoscopy services, and is always looking for ways to improve [30] 


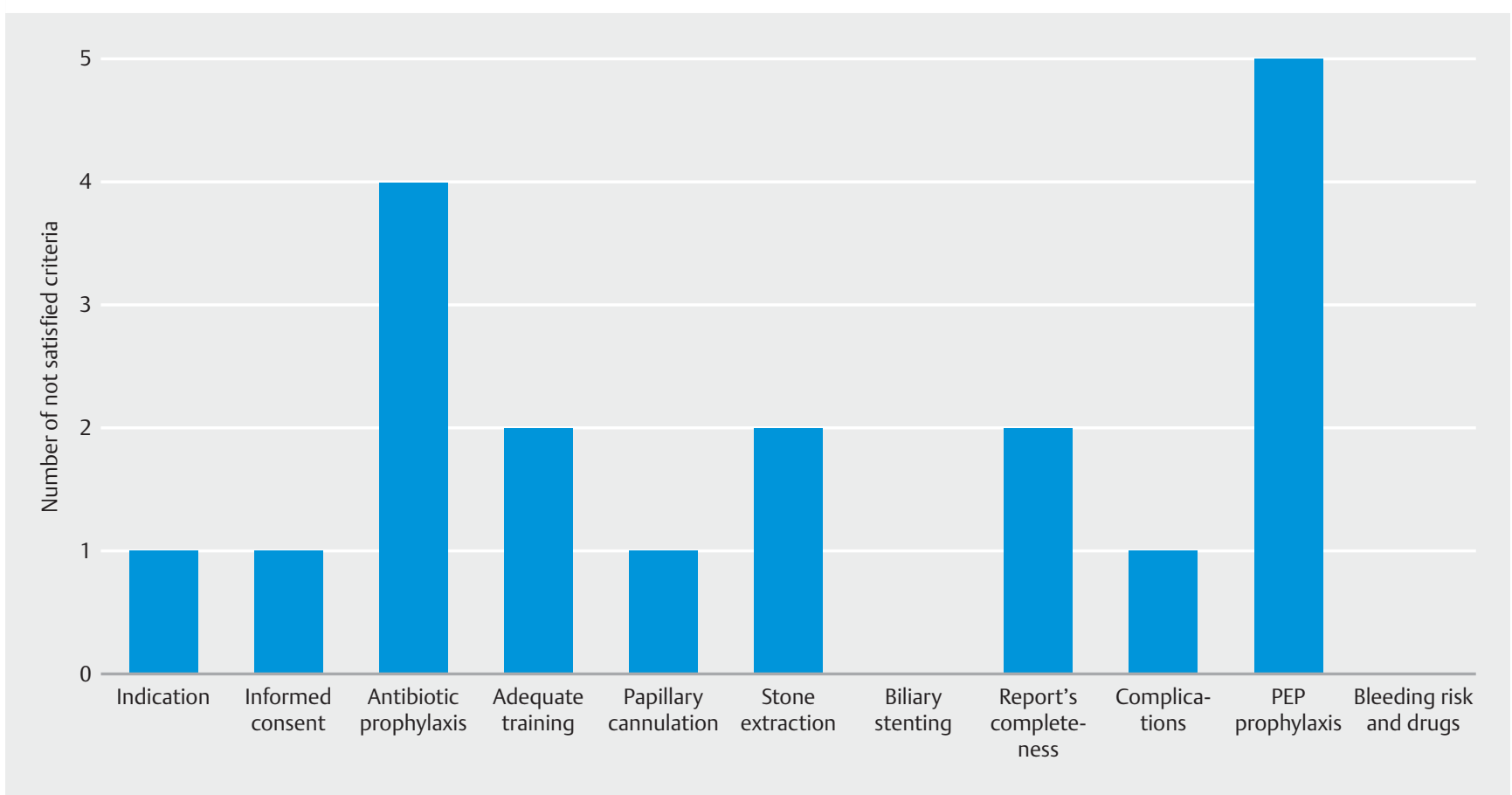

- Fig.6 Quality indicators for ERCP: frequency of criteria not met according to the endoscopic report. Please see Appendix 1 for complete explanation of the criteria.

\section{Conclusions}

Our findings show that numerous Italian endoscopy centers fail to meet important quality standards. SIED accreditation provides a means for detecting and correcting these problems through site visits. Keeping up these standards over time also probably calls for periodic monitoring of the centers, and we have scheduled the first of these at 2 years, then every 3 years from the second onwards.

\section{Acknowledgements}

The authors thank the SIED President Luigi Pasquale and Central SIED Committee and ANoT President Cinzia Rivara for their support. They also thank all endoscopists (Baldassarre G, Bertani H, Boarino V, Coppola F, Currò E, Fasoli R, Germanà B, lerfone $N$, Iori V, Lauri A, Marraccini B, Rando G, Santucci R, Tringali A) and nurses (Berenato E, Di Franco A, Gaggiotti M, Giaquinto A, Guarini A, lannone T, lori G, Marziali B, Minenna A, Valdinoci M, Vecchi E, Zamboni G) engaged in site visits to Italian endoscopy centers. They are grateful to Kiwa-Cermet for technical assistance.

This work is supported by SIED, which had no influence on the study design, conduct, analysis or the final manuscript.

\section{Competing interests}

The authors declare that they have no conflict of interest.

\section{References}

[1] Kohn L, Corrigan J, Donaldson M. To err is human. Building a safer health system Washington DC: Institute of Medicine, National Academies Press; 1999

[2] Johnson MR, Grubber J, Grambow SC et al. Physician non-adherence to colonoscopy interval guidelines in the Veterans Affairs Healthcare System. Gastroenterology 2015; 149: 938-951

[3] van Heijningen EM, Lansdorp-Vogelaar I, Steyerberg EW et al. Adherence to surveillance guidelines after removal of colo-rectal adenomas: a large, community-based study. Gut 2015; 64: 1584-1592

[4] Suman A, Schaafsma FG, van de Ven PM et al. Effectiveness of a multifaced implementation strategy compared to usual care on low back pain guidelines adherence among general practioners. BMC Health Serv Res 2018; 18: 358

[5] Cabana MD, Rand CS, Power NR et al. Why don't physicians follow clinical practice guidelines? A framework for improvement JAMA 1999; 282: 1458-1465

[6] McGlynn EA, Asch SM, Adams ] et al. The quality of health care delivered to adults in the United States. N Engl J Med 2003; 348: 26352645

[7] Veitch AM, Vedo N, Yao K et al. Optimizing early upper gastrointestinal cancer detection at endoscopy. Nat Rev Gastroenterol Hepatol 2015; 12: 660-667

[8] Paggi S, Amato A, Anderloni A et al. Pre and post-procedural quality indicators for colonoscopy. A nationwide survey. Dig Liver Dis 2016; 48: 759-764

[9] Patel N, Tong L, Ahn C et al. Post-polypectomy guideline adherence: importance of belief in guidelines, not guideline knowledge or fear of missed cancer. Dig Dis Sci 2015; 60: 2937-2945

[10] Greenfiled D, Braithwaite J. Health sector accreditation research: a systematic review. Int J Qual Healthcare 2008; 20: 172-183 
[11] Hinchcliff R, Greenfield D, Moldovan M et al. Narrative synthesis of health accreditation literature. BMJ Qual Saf 2012; 21: 979-991

[12] Flodgren G, Goncalves-Bradley DC, Pomey MP. External inspection of compliance with standards for improved healthcare outcomes. Cochrane Database Syst Rev 2016: CD008992

[13] Grol R, Grimshaw J. From best evidence to best practice: effective implementation of change in patients care. Lancet 2003; 362: 12251230

[14] Colbert CY, Diaz-Guzman E, Myers JD et al. How to interpret surveys in medical research: A practical approach. Cleve Clin J Med 2013; 80 : 423-425

[15] Petersen BT, Koch J, Ginsberg GG. Infection using ERCP endoscopes. Gastroenterology 2016; 151: 46-50

[16] O'Horo JC, Farrell A, Sohail MR et al. Carbapenem-resistant Enterobacteriaceae and endoscopy: An evolving threat. Am J Infect control 2016; 44: 1032-1036

[17] Alrabara S. Early identification and control of carbapenemase-producing Klebsiella pneumoniae, originating from contaminated endoscopic equipment. Am J Infect Control 2013; 41: 850

[18] Naas T, Cuzon G, Babics A et al. Endoscopy-associated transmission of carbapenem resistant Klebsiella pneumoniae producing KPC-2 betalactamase. J Antimicrob Chemother 2010; 65: 1306-1316

[19] Tavernise S. Deadly CRE germs linked to hard-to-clean medical scopes. The New York Times February 19, 2015, Page A14

[20] Muller-Staub M, Lunney M, Odenbreit M et al. Development of an instrument to measure the quality of documented nursing diagnosis, interventions and outcomes: the Q-Dio. J Clin Nurs 2009; 18: 10271237

[21] Bjorkman D], Steeblik M. Best practice recommendations for diagnosis and management of Helicobacter pylori: Synthesizing the guidelines. Curr Treat Options Gastroenterol 2017; 15: 648-659
[22] Malfertheiner P, Megraud F, O'Morain CA et al. Management of Helicobacter pylori infection: The Maastricht V/Florence consensus report. Gut 2017; 66: 6-30

[23] Duarte RB, Bernardo WM, Sakai CM et al. Computed tomography colonography versus colonoscopy for the diagnosis of colorectal cancer: a systemic review and meta-analysis. Ther Clin Risk Manag 2018; 14 : 349-360

[24] Rex DK, Boland CR, Dominitz JA et al. Colorectal cancer screening: recommendations for physicians and patients from the U.S. Multisociety Task Force on colorectal cancer. Gastroenterology 2017; 153: 307-323

[25] Kaminski MF, Wieszczy P, Rupinski M et al. Increased rate of adenoma detection associates with reduced risk of colorectal cancer and death. Gastroenterology 2017; 153: 98-105

[26] Mysliwiec PA, Brown ML, Klabunde CN et al. Are physicians doing too much colonoscopy? A national survey of colorectal surveillance after polypectomy Ann Intern Med 2004; 141: 264-271

[27] Bisschops R, Arela M, Coron E et al. Performance measures for upper gastrointestinal endoscopy: a European Society of Gastrointestinal Endoscopy (ESGE) quality improvement initiative. Endoscopy 2016; 48: 843-864

[28] Valori R, Thomas-Gibson S. Commentary: accrediting colonoscopy services and colonoscopists for screening makes a difference. Colorectal Dis 2018; 20: O283-O285

[29] Deirdre MN, Wright Ballester A, Valentelyte G et al. The contribution of endoscopy quality measures to the development of interval colorectal cancers in the screening population: a systematic review. Int J Colorectal Dis 2019: 34

[30] Valori R. Joint Advisory Group on Gastrointestinal endoscopy (JAG) achieves enduring large-scale change. Frontline Gastroenterol 2019; 10: $91-92$ 